\title{
RETOS Y DESAFÍOS DE LAS ACTIVIDADES PRODUCTIVAS EN LAS COMUNIDADES INDÍGENAS DEL DEPARTAMENTO DEL CAUCA EN EL MARCO DEL POSCONFLICTO*
}

\section{CHALLENGES AND DARE OF PRODUCTIVE ACTIVITIES IN THE NATIVES COMMUNITIES OF THE DEPARTMENT OF CAUCA IN THE POST-CONFLICT FRAMEWORK}

Recibido: 16 de octubre de 2018

Evaluado: 18 de diciembre de 2018

Aprobado: 16 de enero de 2019

\author{
Marilu Avendaño Avendaño** \\ Universidad Nacional Abierta y a Distancia-UNAD \\ Orcid: https://orcid.org/0000-0001-7578-5816 \\ Andrey Eduardo Galvis Pérez ${ }^{\star * *}$ \\ Rama Judicial-Dirección Ejecutiva Seccional de Administración Judicial de Popayán-DESAJ, Popayán. \\ Orcid: https://orcid.org/0000-0003-0048-6904 \\ Diego Edisson Velasco Hurtado**** \\ Corporación Universitaria Comfacauca-Unicomfacauca \\ Orcid: https://orcid.org/0000-0002-2654-4730
}

Cómo citar este artículo: Avendaño Avendaño, M., Galvis Pérez, A. E. y Velasco Hurtado, D. E. (2019). Retos y desafíos de las actividades productivas en las comunidades indígenas del departamento del Cauca en el marco del posconflicto. Revista Estrategia Organizacional, 8 (1). doi: https://doi.org/10.22490/25392786.3176

\footnotetext{
* $\quad$ Artículo de investigación. Resultado de la investigación sobre las problemáticas en las actividades productivas de las comunidades indígenas del departamento del Cauca en el marco de la Maestría en Administración de las Organizaciones.

** Docente de la Universidad Nacional Abierta y a Distancia - UNAD, Administradora de empresas, especialista en Gestión de proyectos, especialista en educación superior a distancia. Magíster en Educación, Investigadora del Grupo GIEPE. Google Scholar: https://scholar.google.es/citations?user=_anOzf4AAAAJ\&hl=es Correo electrónico: marilu.avendano@unad.edu.co

*** Coordinador Área Administrativa. Administrador de Empresas, Especialista en Educación con Nuevas Tecnologías de la Información y la Comunicación, Magister en Administración de Organizaciones. Siete años de experiencia en docencia en la Universidad Nacional, Abierta y a Distancia - UNAD; Once años de experiencia como Asesor Académico y Administrativos en el Programa de Formación en Idiomas (PFI) de la Universidad del Cauca. Correo electrónico: aegalvis@gmail.com

**** Administrador de Empresas, Especialista en Gerencia Estrategica de Mercadeo, Magíster en Administración de las Organizaciones de la Universidad Nacional. Correo electronico: develasco_@hotmail.com
} 


\title{
RESUMEN
}

La investigación que se presenta en este artículo identifica necesidades o problemáticas en las actividades productivas de las comunidades indígenas del departamento del Cauca. Se hará la descripción del estado del arte para documentar la evolución de las actividades productivas a partir de la violencia ocasionada por el conflicto armado. Se hace una revisión y análisis de procesos de paz similares que se hayan llevado a cabo en otros países de la región y que hayan fortalecido de alguna manera actividades productivas. Se entrevistaron expertos que a través de diferentes instrumentos de recolección de datos y con el uso de herramientas prospectivas como el Método Delphi permitirán realizar un análisis de la percepción y visión que tienen de las actividades productivas que realizan las comunidades indígenas del departamento del Cauca a partir del postconflicto, visualizando esos retos y desafíos que traerá el fin del conflicto armado en Colombia. Se realiza la identificación de variables para la aplicación del método MICMAC donde se identificarán variables clave y, a través del método MACTOR, se identifican los actores sociales que intervienen en el tema de investigación con el propósito de construir posibles escenarios a los que se enfrentarán las comunidades indígenas del departamento del Cauca en cuanto a sus actividades productivas. Se realiza un plan estratégico con su respectivo plan de acción donde se tendrán en cuenta las estrategias, metas, objetivos, actores involucrados, plan de seguimiento que sirva a la población objeto de estudio, para hacer frente a los retos y desafíos que trae la firma de la paz y fin del conflicto armado en Colombia y su contribución al fortalecimiento de las actividades productivas de las comunidades indígenas del departamento del Cauca.

Palabras clave: producción, estructura, gobierno, administración, Cauca, indigena, posconflicto.

\begin{abstract}
The investigation presented in this article identifies the needs or problems in the productive activities of the indigenous communities of the department of Cauca. The description of the state of the art will be made to document the evolution of productive activities stemming from the violence caused by the armed conflict. There is a review and analysis of similar peace processes that have been carried out in other countries of the region that have, in some way, strengthened productive activities. Experts were interviewed who, through different data collection instruments and with the use of prospective tools such as the Delphi Method, allow for the analysis of their perception and vision of the productive, post-conflict activities carried out by the indigenous communities of
\end{abstract}


the department of Cauca; visualising the challenges that the end of the armed conflict in Colombia will bring. The identification of variables for the application of the MICMAC method is performed. Here, key variables will be identified and, through the MACTOR method, the social actors that intervene in the research topic are identified with the purpose of constructing possible scenarios for the indigenous communities of the department of Cauca in terms of their productive activities. A strategic plan is made with its respective action plan which will take into account the strategies, goals, objectives, actors involved and monitoring plan that serves the target population, to face the challenges of the post conflict period in Colombia and contributing to the strengthening of productive activities of the indigenous communities of the department of Cauca.

Keywords: production, structure, government, Cauca, indigenous, post-conflict.

\section{INTRODUCCIÓN}

Esta investigación identifica las principales necesidades, retos y desafíos de las actividades productivas a las que se dedican las comunidades indígenas del departamento del Cauca, a través de un plan prospectivo como estrategia competitiva al año 2030. El conflicto armado en Colombia ha sido sinónimo de violencia y ha golpeado por más de medio siglo al país, y las comunidades indígenas del departamento del Cauca no han sido ajenas a este flagelo. Es por eso que este trabajo busca responder a la pregunta ¿cuáles serán los retos y desafíos a los cuales deberán enfrentarse las actividades productivas de las comunidades indígenas del departamento del Cauca, ante el fin del conflicto armado en Colombia? Lo anterior, teniendo en cuenta que hasta el momento no se han definido por parte del gobierno nacional, programas y planes para el manejo del posconflicto en las actividades productivas de las comunidades indígenas del departamento del Cauca. Así mismo es importante analizar la evolución histórica del conflicto armado en las comunidades indígenas del departamento del Cauca y su impacto en las actividades productivas.

Desde el 2005 se vienen presentando acciones de grupos emergentes y rearmados en el departamento, la Organización Nueva Generación (ONG), los Rastrojos, las Águilas Negras se ubican en la zona. "En el departamento de Cauca, los estudios y las entrevistas dan cuenta que la ONG tiene también incidencia en la zona del Alto Patía en los municipios de Argelia, El Bordo, El Tambo y que 
a su turno los Rastrojos inciden en los municipios costeros de Guapi, Timbiquí y López de Micay y se relacionan con la presencia del narcotráfico" (Fundación Seguridad y Democracia, 2008, p. 6).

Es por esto que la Universidad Nacional, Abierta y a Distancia-UNAD no puede ser ajena al proceso de paz y con los conocimientos tanto de docentes como estudiantes a través de la utilización de herramientas prospectivas, se deben diseñar escenarios futuros para las actividades productivas de las comunidades indígenas del departamento del Cauca. Lo anterior para tener algunos recursos a través de la planeación de su futuro y diseño de su plan de vida, en medio de estos escenarios de paz. Ello contribuirá no solo al mejoramiento de la calidad de vida desde lo social, educativo, cultural, y político sino también al crecimiento y desarrollo económico de las comunidades y del departamento del Cauca.

Para el desarrollo de este ejercicio prospectivo, se propone la utilización del Modelo de Prospectiva Social Participativa que Mera y Avendaño (2013) han adaptado de los modelos de Godet, (2000) y Francisco José Mojica (2008).

A través de la aplicación de las herramientas prospectivas, este modelo permite: la identificación de necesidades para visualizar las variables y actores que intervienen en las actividades productivas y la construcción de escenarios, que permitirán prever posibles soluciones o mitigaciones a esas problemáticas o necesidades. Como prepararse para afrontar de forma adecuada los retos y desafíos del futuro a través del plan estratégico que se plantea para el fortalecimiento de las actividades productivas de las comunidades indígenas del departamento del Cauca.

\section{MARCO TEÓRICO}

En el marco del conflicto armado vivido en Colombia, desde hace algunas décadas, se ha comenzado el posconflicto, definido éste como la fase que viene después de la firma definitiva de los acuerdos de paz, pero que en algún sentido es deseable construir durante el conflicto, y que supone una recomposición de la sociedad que incluye asuntos como la desmovilización de los actores armados, la seguridad ciudadana, la reinserción y el desarrollo de los acuerdos de paz (Gomez, 2003).

Ahora bien, dado que resulta un poco complejo dar una definición de posconflicto exacta; se puede describir como "El periodo de tiempo en el cual las hostilidades del pasado se han reducido al nivel necesario para que las actividades de reintegración y rehabilitación se puedan iniciar" (Paula San Pedro. 2006, p. 3). 
Donde se requiere principalmente el cese de la violencia, el cual se refleja en un acuerdo de paz en el que la sociedad haya superado el daño no solo físico sino mental; aprendiendo a olvidar y perdonar, sanando a su vez las heridas tanto individual como colectivamente; con la práctica de acciones no solo políticas, sino sociales y académicas.

Los procesos de paz en Colombia arrojan los límites de las distintas apuestas por una paz estable y extendida a los distintos ámbitos de la vida cotidiana. El objeto de una negociación es la salida de la confrontación, la necesidad de que nuevas fuerzas sociales participen, no solo en la implementación de eventuales acuerdos, sino en el diseño de esos convenios, y de las dimensiones sociales donde deberían producir transformaciones, sobre la base de acuerdos políticos plurales que mantengan abierta la posibilidad de su reforzamiento durante un tiempo prolongado (Cárdenas, 2003).

Esto nos hace pensar si Colombia tiene preparado un sinnúmero de escenarios y estrategias para abordar de manera eficaz el momento en que se acabe el conflicto y se quieran fortalecer las actividades productivas o si, por el contrario, estamos buscando un fin sin saber cómo enfrentarlo.
El conflicto armado se convirtió en una nube, por décadas ha escondido otros problemas medulares del departamento como la concentración de la propiedad rural en manos de hacendados e industriales, las concesiones mineras, la minería ilegal, los conflictos entre indígenas, afros y campesinos por la tierra, y los errores que cometió el Instituto Colombiano de Desarrollo Rural (INCODER) a la hora de comprar y titular predios.

La educación para la paz debe propiciar escenarios que contribuyan a la comprensión de los conflictos, su análisis y trasformación. Pero ante todo "ha de ser también una educación para el encuentro de las individualidades, una educación para la conspiración, la cooperación, la cesión de confianza, un lugar donde aprender el manejo de nuestras potencialidades de transformación y en donde los proyectos culturales se conviertan en actividad política" (Fisas, 2006, p. 376).

La prospectiva estratégica no solo maneja fenómenos, sino que en su búsqueda por interpretar verosímilmente la realidad se lanza a reconocer los grupos humanos o "actores sociales" que están ocultos detrás de los fenómenos estudiados. Por esta razón, en esta investigación se estudia el comportamiento de los actores sociales que tienen relación con las variables estratégicas, se reconocen los retos 
implícitos o explícitos que están afrontando y se precisan las posibles jugadas o estrategias, como si se tratara de una partida de ajedrez.

- Actividad productiva: vista la actividad productiva como el proceso de transformación de materias primas en productos terminados.

- Reto: es un objetivo o una acción que tendrá dificultades para llevar a cabo, toda vez que supone un estímulo y un desafío.

- Desafío: hace referencia a los planteamientos o situaciones a los que debe enfrentarse una persona o comunidad ante un cambio inminente.

Fred (2003) define estrategia como los medios para lograr los objetivos. Por otra parte, Drucker (1994) fue uno de los primeros en mencionar el término estrategia en la administración, para él, estrategia de la organización era la respuesta a dos preguntas: ¿qué es nuestro negocio? y ¿qué debería ser? Mintzberg (1997) plantea que la estrategia es el patrón o plan que integra las principales metas y políticas de una organización, y, a la vez, establece la consecuencia coherente de las acciones por realizar.

Miklos (2001), por su parte, define la planeación estratégica como el esfuerzo sistemático, y más o menos formal, de una institución u organización para establecer sus propósitos, sus objetivos, sus políticas y sus estrategias básicas, con el fin de desarrollar planes detallados que pongan en práctica las políticas y las estrategias que la lleven a lograr sus objetivos y sus propósitos fundamentales.

Godet (1990) define el "Planeamiento Estratégico Prospectivo como un nuevo enfoque de Planeamiento que consiste en guiar a todos los Planeamientos Estratégicos de la organización hacia un futuro, creando escenarios futuros que desea alcanzar la organización, tomando medidas correctivas para un presente más deseado y para alcanzar aquel escenario posible, deseable y probable".

\section{METODOLOGÍA}

Para el desarrollo de este ejercicio prospectivo, se propone la utilización del Modelo de Prospectiva Social Participativa (figura 1) que los profesores Mera y Avendaño (2013) han adaptado de los modelos de Godet, (2000) y Francisco José Mojica (2008). A través de la aplicación de las herramientas prospectivas este modelo permite: la identificación de necesidades o problemas, de variables y actores y permite la construcción de escenarios donde se proveen posibles soluciones o mitigaciones y lo más importante proponer un plan estratégico para afrontar de forma adecuada los retos y desafíos del futuro de las actividades productivas de las comunidades indígenas del departamento del Cauca. 


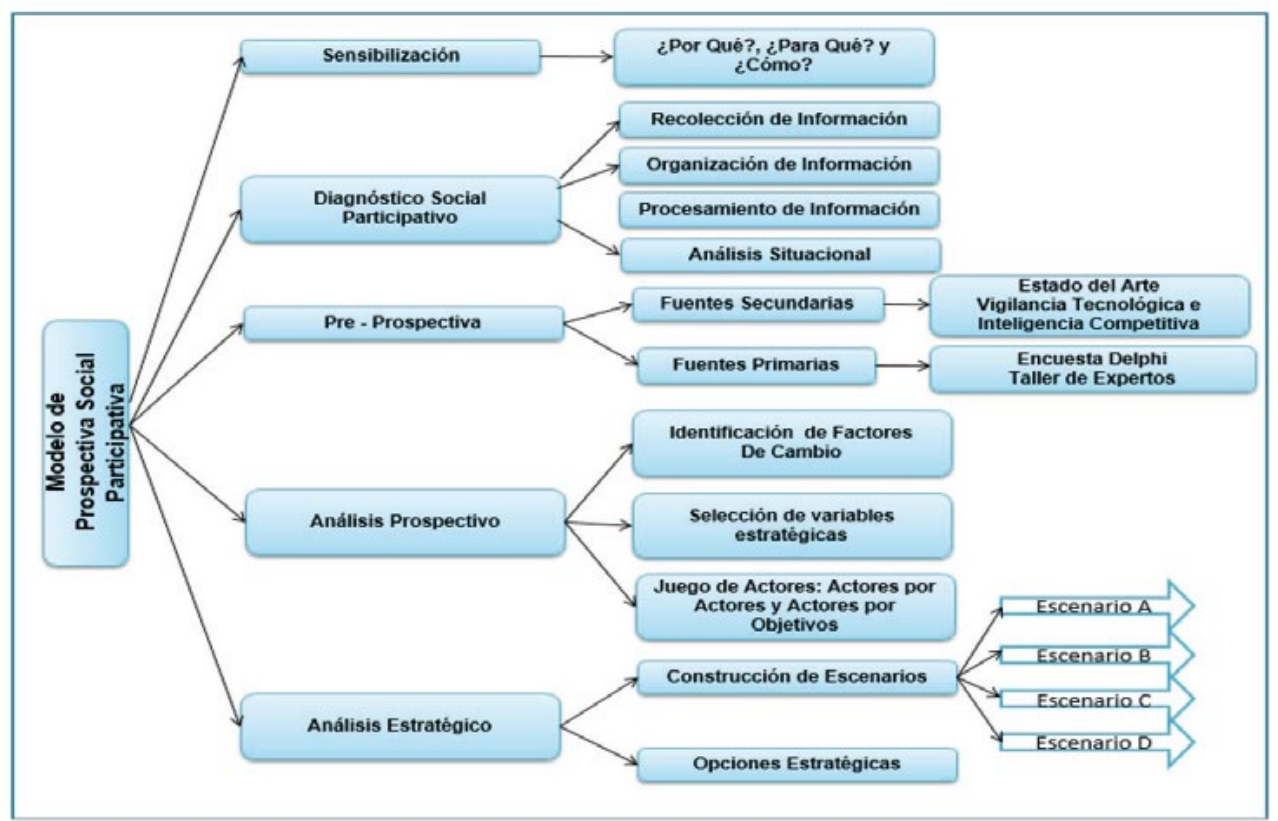

Figura 1. Modelo de prospectiva social y participativa.

Fuente: Mera, y Avendaño (2013)

El modelo de prospectiva social participativa consta de cinco fases. La primera consiste en hacer la sensibilización de los expertosy actores sociales, qué es y para qué sirve la prospectiva y la importancia de los talleres. La segunda el diagnóstico social participativo que tiene por objetivo identificar las necesidades y problemáticas que se desarrollan en el objeto de estudio. La tercera fase denominada pre-prospectiva donde se realiza toda la recolección de información a través de fuentes primarias y secundarias. La cuarta de análisis prospectivo en la cual se identifican los factores de cambio, se seleccionan las variables estratégicas y se determina el rol de los actores. La quinta fase se encarga de la y construcción de escenarios y el diseño del plan prospectivo y estratégico.

\section{RESULTADOS}

Dentro de las fuentes primarias se realizó un panel a expertos sobre el tema de posconflicto y el futuro de las actividades productivas en las comunidades indígenas. Los integrantes del panel fueron seleccionados en calidad de expertos, representantes de actores como: universidades -decanos, tutores, catedráticos, estudiantes, entre otros $-\mathrm{y}$ vinculados al sector; representantes de comunidades indígenas (CRIC, cabildos 
indígenas); representantes de comunidades afro descendientes (Costa Pacífica) y representantes de la Iglesia, periodismo, policía, alcaldías.

A continuación, se exponen los resultados obtenidos después del análisis de las participaciones de los expertos, organizados según los distintos bloques temáticos en torno a los cuales se ha recogido la información. Se organizaron los resultados en función del grado de ocurrencia, se detalla, en cada caso, la influencia previsible que tendría para los retos y desafíos de las actividades productivas de las comunidades indígenas del departamento del Cauca en el marco del posconflicto al año 2030 :

1. ¿Qué grado de importancia le asignaría usted a los siguientes factores de cambio para enfrentar los retos y desafíos de las actividades productivas de las comunidades indígenas del departamento del Cauca en el marco de posconflicto al año 2030?

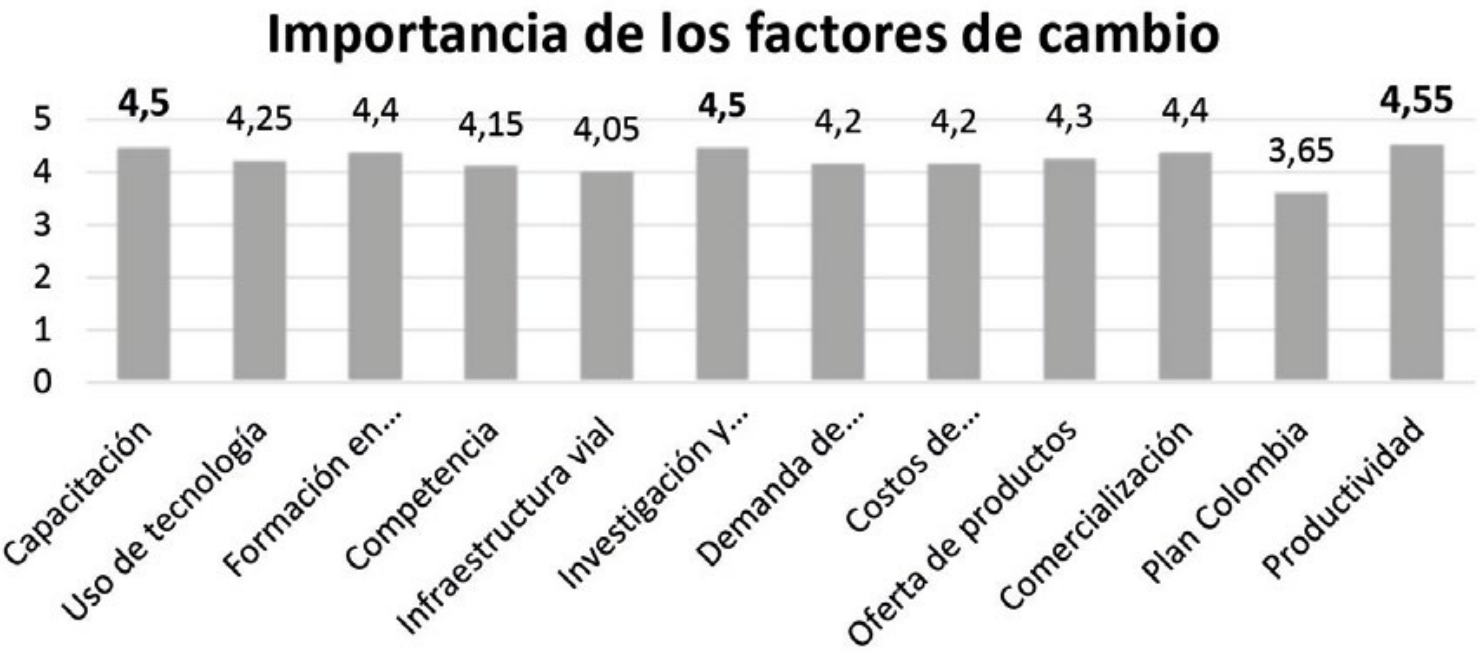

Figura 2. Pregunta 1 Cuestionario DELPHI.

Fuente: elaboración propia

El personal experto al cual se le aplicó la encuesta y teniendo en cuenta el estudio prospectivo al año 2030, sugiere que los más importantes factores de cambio para el fortalecimiento de las actividades productivas de las comunidades indígenas son la capacitación, la investigación y desarrollo, la productividad y la infraestructura para la comercialización de productos. Las 
comunidades indígenas del departamento del Cauca deben conocer a fondo el cuidado y los procesos que deben tener con la preparación de las tierras para que sean fértiles y productivas, deben conocer sobre cadenas productivas y asociatividad, técnicas de siembra, cuidado y recolección de alimentos, trabajo en equipo, protección del medio ambiente y logística y transporte de productos. Con estos conocimientos se lograra un efectivo desarrollo rural en las comunidades indígenas que generaran una mejor calidad de vida para sus habitantes y los productos ofrecidos serán de calidad y confianza para sus clientes.

2. ¿Qué grado de importancia le asignaría usted a los siguientes actores, para los retos y desafíos de las actividades productivas de las comunidades indígenas del departamento del Cauca en el marco de posconflicto al año 2030 ?

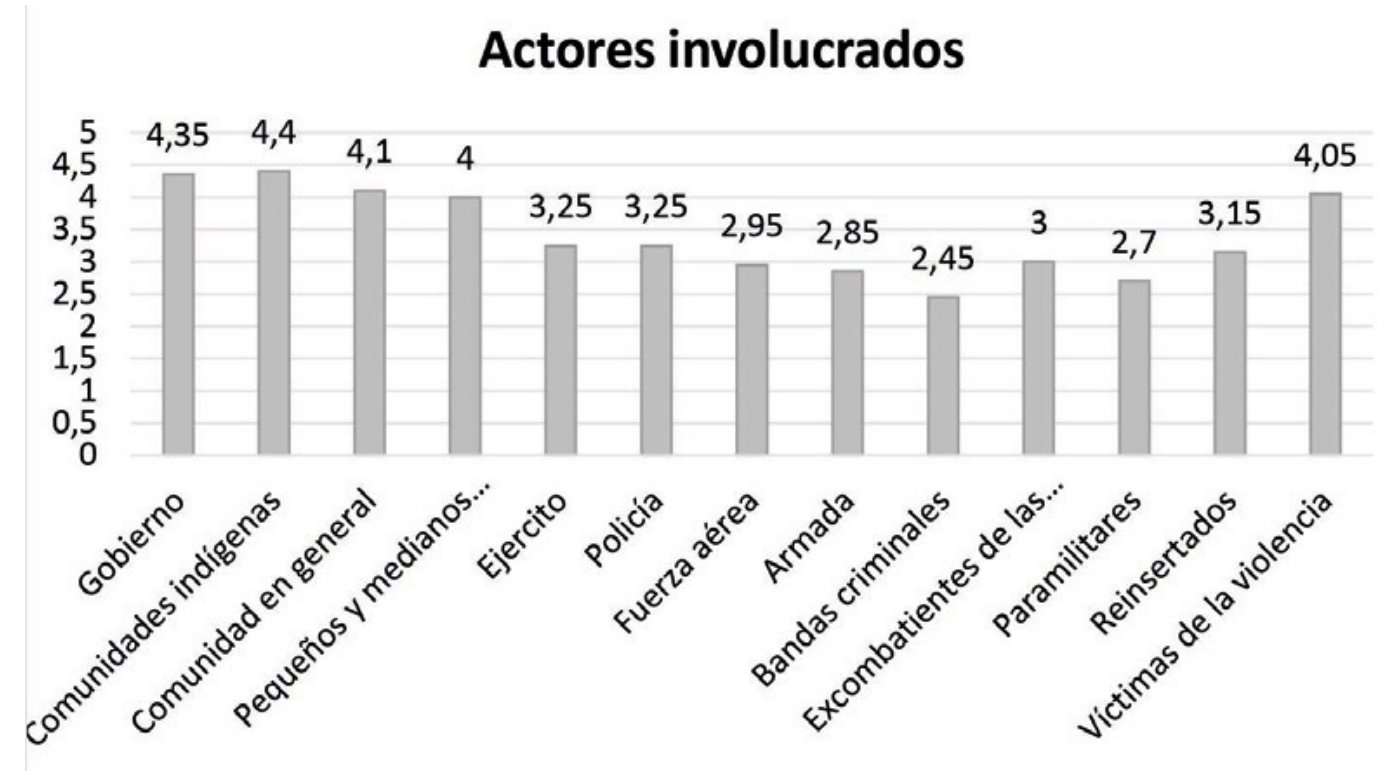

Figura 3. Pregunta 2 Cuestionario DELPHI.

Fuente: elaboración propia

Los actores más representativos para lograr un Cauca son: el gobierno, las mismas comunidesarrollo de las actividades productivas de las dades indígenas y las víctimas de la violencia. comunidades indígenas del departamento del Este punto es muy importante ya que agrupa los 
verdaderos actores que al transcurrir el tiempo se han visto involucrados en las actividades productivas que desarrollan las comunidades indígenas y además han contribuido para que los acuerdos de paz puedan hacerse realidad y Ileguen a feliz término, los expertos se centraron potencialmente en el gobierno, las comunidades indígenas y las víctimas de la violencia.

En el caso del gobierno no se puede descuidar la conformación y el trabajo que se viene adelantando en los consejos de paz en los municipios y departamentos del territorio nacional. Por el contrario se deben reactivar y fortalecer ya que es un escenario de participación ciudadana "El más representativo y plural para tratar el tema de la paz y sus acuerdos, como lo es el de la reforma rural integral; así mismo las comunidades indígenas y a la vez víctimas de la violencia generada en estos más de cincuenta años son eje fundamental para la reconstrucción del país, por eso el gobierno debe manejar los recursos destinados a las actividades productivas de los sectores que han sido más golpeados por los grupos al margen de la ley y que se apoderaron de tierras y de familias enteras causándoles dolor y hasta la muerte, para que desarrollen sus proyectos productivos en las tierras de las que un día fueron dueños y así puedan obtener ingresos económicos que mejoren su calidad de vida.

3. ¿Qué grado de importancia le asignaría usted a las siguientes líneas productivas desarrolladas por las comunidades indígenas del departamento del Cauca?

\section{Líneas productivas de las comunidades indígenas}
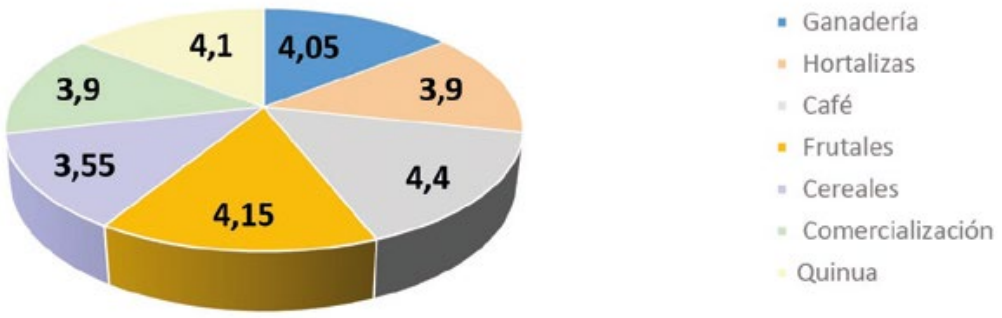

Figura 4. Pregunta 3 Cuestionario DELPHI.

Fuente: elaboración propia 
El cultivo de café, frutales y quinua y la comercialización de los mismos son las actividades que según los expertos contribuirán al desarrollo de las actividades productivas de las comunidades indígenas del departamento del Cauca.

Los expertos encuestados ven en el Café un producto potencial que beneficiaría a las comunidades indígenas del cauca, ya que alberga al $26 \%$ de la población indígena del país y en su territorio se encuentra en 86 de los 549 resguardos indígenas que hay en Colombia, es por esto que el café está dentro de los tres grandes proyectos que se desprenden del proceso de paz y que fueron anunciados por el Ministro del Posconflicto Rafael Pardo para el Norte del Cauca, buscando la ampliación del cultivo del café y el mejoramiento de su calidad para potenciar el acceso a nuevos mercados. Así mismo la Quinua es otro producto que está bien perfilado en el mercado nacional y que según los expertos le dan un alto grado de aceptación en las líneas productivas desarrolladas por las comunidades indígenas del Cauca, convirtiéndose en una alternativa de ingresos para un gran número de familias caucanas".

4. ¿Cuál considera usted que será la tendencia de las actividades productivas de las comunidades indígenas del departamento del Cauca durante los próximos 15 años y en un escenario de paz?

\section{Tendencias de las actividades productivas}

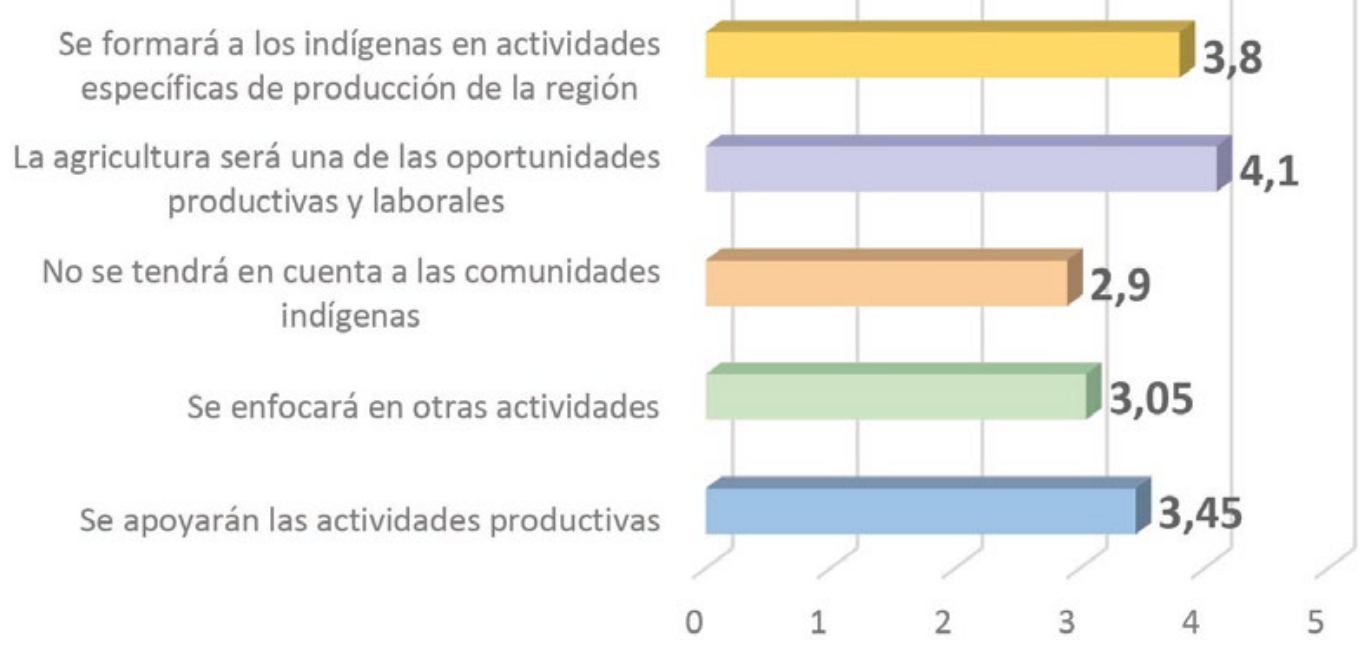

Figura 5. Pregunta 4 Cuestionario DELPHI.

Fuente: elaboración propia 
Según los expertos, la agricultura será una de las oportunidades productivas y laborales, que contribuirá con el desarrollo de las actividades productivas de las comunidades indígenas del departamento del Cauca. Potencialmente la tendencia se enfocara en la agricultura como oportunidad productiva y laboral para las comunidades indígenas del departamento del Cauca en los próximos 15 años, sin descuidar que para que sea exitoso este proceso se debe formar a los indígenas en actividades específicas de producción de la región según señalaron los expertos en la encuesta desarrollada y así lograr bajar las tasas de desempleo en el Cauca y asegurar una sana convivencia entre indígenas y reinsertados para generar un escenario de paz.

5. Usted considera que las actividades productivas a partir del posconflicto se pueden ver afectadas por:

\section{Afectación de las actividades productivas}

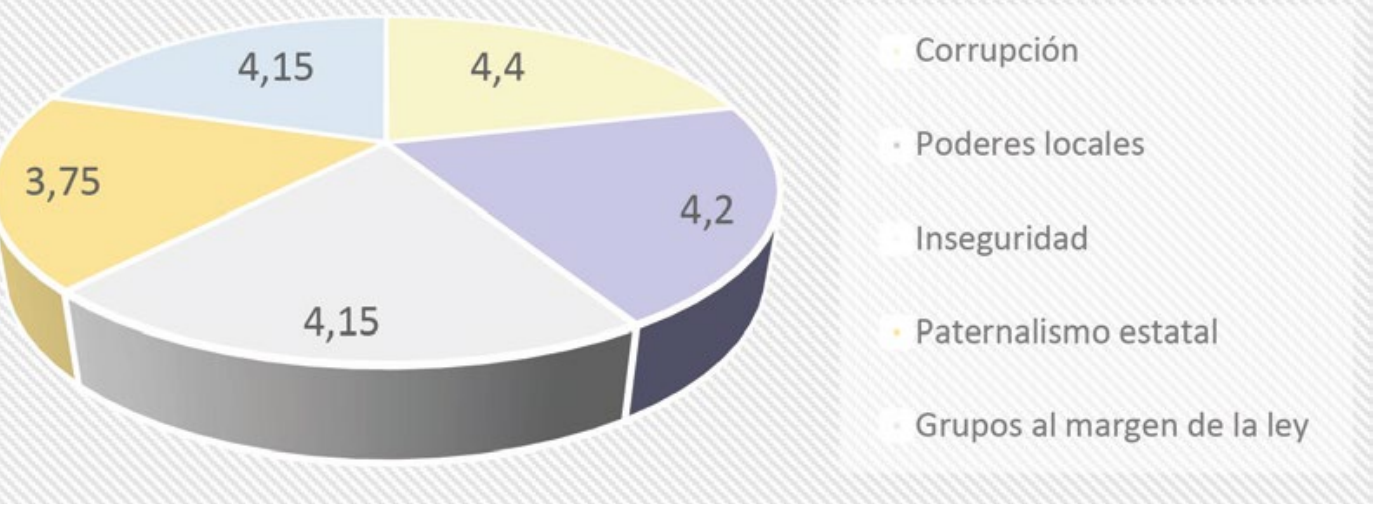

Figura 6. Pregunta 5 Cuestionario DELPHI.

Fuente: elaboración propia

La corrupción será según los expertos, el factor que podrá afectar el desarrollo de las actividades productivas de las comunidades indígenas en el departamento del Cauca. Según el personal de expertos consultados y teniendo presente que la mayoría son habitantes de los pueblos indígenas y campesinos más golpeados por la violencia en el departamento del Cauca, afirman que la corrupción y los poderes locales seguirán beneficiándose y arrebatándole lo que les corresponde a sus comunidades en el caso de las actividades productivas y de 
los recursos que supuestamente invertirá el gobierno según el punto uno de la reforma rural integral contemplados en los acuerdos de paz.

\section{ANÁLISIS ESTRUCTURAL MICMAC}

Mojica (1991) dice que el análisis estructural es una técnica del estructural funcionalismo donde se define a la estructura como una realidad que es estudiada como un sistema, cuyos elementos guardan relaciones de interdependencia.
A continuación, se presentan los factores de cambio para los retos y desafíos de las actividades productivas de las comunidades indígenas del departamento del Cauca, donde la red de interrelaciones de estos elementos, es la configuración del sistema -estructura- que constituye la clave de sus dinámicas y es bastante permanente. MicMac (Godet, 2000, p. 76).

Tabla 1. Variables estratégicas para las actividades productivas.

\begin{tabular}{|c|c|c|c|c|}
\hline $\mathbf{N}^{\circ}$ & Nombre Largo & Nombre corto & Descripción & Tema \\
\hline 1 & Capacitación & CAPAC & $\begin{array}{l}\text { Capacitación en todos los temas que se requiera } \\
\text { para que los integrantes de las comunidades } \\
\text { indígenas del Departamento del Cauca puedan } \\
\text { obtener las competencias en diferentes áreas y } \\
\text { así estar preparados para adelantar actividades } \\
\text { productivas. }\end{array}$ & Educativo \\
\hline 2 & Uso de tecnología & TEC & $\begin{array}{l}\text { Incorporación de tecnología tanto alos procesos } \\
\text { de formación como de producción. }\end{array}$ & Tecnológico \\
\hline 3 & Política & POL & $\begin{array}{l}\text { Tienen que ver con la administración del poder } \\
\text { y las relaciones sociales al interior de las } \\
\text { comunidades indígenas del Departamento del } \\
\text { Cauca }\end{array}$ & Social \\
\hline 4 & Formación específica & FORMES & $\begin{array}{l}\text { Formación en temas específicos que hayan } \\
\text { sido previamente identificados por las mismas } \\
\text { comunidades. }\end{array}$ & Educativo \\
\hline 5 & Competencia & COMPE & $\begin{array}{l}\text { Este factor tiene que ver con la identificación de } \\
\text { otras organizaciones que se dediquen a labores } \\
\text { similares a las que desarrollan las comunidades } \\
\text { indígenas. }\end{array}$ & Económico \\
\hline 6 & Infraestructura vial & INFRV & $\begin{array}{l}\text { Estado de las vías de acceso desde los centros } \\
\text { urbanos y de comercialización hasta los lugares } \\
\text { de habitación de las comunidades indígenas del } \\
\text { Departamento del Cauca. }\end{array}$ & $\begin{array}{l}\text { Tecnológico } \\
\text { Económico }\end{array}$ \\
\hline
\end{tabular}




\begin{tabular}{|c|c|c|c|c|}
\hline $\mathbf{N}^{\circ}$ & Nombre Largo & Nombre corto & Descripción & Tema \\
\hline 7 & $\begin{array}{l}\text { Infraestructura para } \\
\text { comercialización }\end{array}$ & INFRCOM & $\begin{array}{l}\text { Estado de todas las fases de la cadena productiva } \\
\text { que puedan garantizar una adecuada estructura } \\
\text { para la comercialización. }\end{array}$ & $\begin{array}{l}\text { Tecnológico } \\
\text { Económico }\end{array}$ \\
\hline 8 & Sociales & SOC & $\begin{array}{l}\text { Todos los aspectos que tengan qie ver con } \\
\text { la conformación de las comunidades y que } \\
\text { se consideren para el cambio a un estado en } \\
\text { condiciones diferentes. }\end{array}$ & Social \\
\hline 9 & Culturales & CULT & $\begin{array}{l}\text { Aspectos que se deben considerar y que estén } \\
\text { relacionados con el comportamiento natural de } \\
\text { los miembros de las comunidades indígenas del } \\
\text { Departamento del Cauca }\end{array}$ & $\begin{array}{l}\text { Social } \\
\text { Cultural }\end{array}$ \\
\hline 10 & $\begin{array}{l}\text { Demanda de productos } \\
\text { agrícolas }\end{array}$ & DEPAG & $\begin{array}{l}\text { Demanda de los productos agrícolas que son } \\
\text { producidos por las comunidades indígenas en el } \\
\text { Departamento del Cauca }\end{array}$ & Económico \\
\hline 11 & Costos de producción & COSTP & $\begin{array}{l}\text { Costos en los que incurren las comunidades } \\
\text { indígenas del Departamento del Cauca para la } \\
\text { producción de los productos agrícolas. }\end{array}$ & Económico \\
\hline 12 & Oferta de productos & OFERP & $\begin{array}{l}\text { Disponibilidad de los productos agrícolas } \\
\text { que producen las comunidades indígenas } \\
\text { del Departamento del Cauca y que ponen a } \\
\text { disposición del mercado. }\end{array}$ & Económico \\
\hline 13 & Comercialización & COMER & $\begin{array}{l}\text { Proceso durante el cual se lleva el producto } \\
\text { terminado al consumidor final. }\end{array}$ & Económico \\
\hline 14 & $\begin{array}{l}\text { Mecanismos de } \\
\text { información }\end{array}$ & MECAIN & $\begin{array}{l}\text { Mecanismos con los que cuentan las } \\
\text { comunidades indígenas del Departamento del } \\
\text { Cauca para mantenerse informados. }\end{array}$ & Tecnológico \\
\hline 15 & Plan Colombia & PLANC & $\begin{array}{l}\text { Es el plan con el que los Estados Unidos apoyará } \\
\text { económicamente en los temas de postconflicto } \\
\text { en Colombia }\end{array}$ & Económico \\
\hline 16 & Productividad & PRODUC & $\begin{array}{l}\text { Búsqueda de las formas de lograr una mayor } \\
\text { producción a unos menores costos, lo cual } \\
\text { favorecerá a las comunidades indígenas del } \\
\text { Departamento del Cauca. }\end{array}$ & Económico \\
\hline 17 & Precios & $\mathrm{PCIO}$ & $\begin{array}{l}\text { La fijación de precios de los productos a cultivar } \\
\text { en las comunidades indígenas de acuerdo a la } \\
\text { oferta y demanda, su posición y los volúmenes de } \\
\text { venta }\end{array}$ & Económico \\
\hline 18 & Convivencia & CVNCIA & $\begin{array}{l}\text { El respeto mutuo entre los actores del Gobierno, } \\
\text { las comunidades indígenas y reinsertados en el } \\
\text { medio en el cual se involucran }\end{array}$ & Social \\
\hline
\end{tabular}

continúa 


\begin{tabular}{|c|c|c|c|c|}
\hline $\mathbf{N}^{\circ}$ & Nombre Largo & Nombre corto & Descripción & Tema \\
\hline 19 & $\begin{array}{l}\text { Acompañamiento } \\
\text { Psicológico }\end{array}$ & $\begin{array}{l}\text { ACTO } \\
\text { PSLGCO }\end{array}$ & $\begin{array}{l}\text { Apoyo a los actores involucrados a través } \\
\text { de charlas, entrevistas relacionadas a la } \\
\text { perturbación o desequilibrio emocional. }\end{array}$ & Educativo. \\
\hline 20 & Trabajo en Equipo & TEPO & $\begin{array}{l}\text { Unión de Comunidades Indígenas, Gobierno y } \\
\text { Reinsertados para el logro de los objetivos de las } \\
\text { actividades productivas. }\end{array}$ & Educativo. \\
\hline 21 & Empleabilidad & EMPBIDAD & $\begin{array}{l}\text { De acuerdo a las aptitudes actitudes de } \\
\text { los actores para el buen desempeño de las } \\
\text { actividades productivas. }\end{array}$ & Económico \\
\hline 22 & $\begin{array}{l}\text { Tiempos y } \\
\text { Movimientos }\end{array}$ & TPO Y MVTO & $\begin{array}{l}\text { Herramienta para la medición del trabajo y } \\
\text { eliminar los movimientos innecesarios en busca } \\
\text { de la productividad }\end{array}$ & Económico \\
\hline 23 & Reuniones Periódicas & RNES PCAS & $\begin{array}{l}\text { Para tener actualizados a los actores, motivados y } \\
\text { planes a seguir. }\end{array}$ & Educativo \\
\hline 24 & Medio Ambiente & MDO AMBTE & $\begin{array}{l}\text { Impulsa una relación de respeto con la naturaleza } \\
\text { y los suelos donde se va a cultivar los productos. }\end{array}$ & Social \\
\hline 25 & La Corrupción & CPCION & $\begin{array}{l}\text { Mal uso del poder público para tomar ventajas de } \\
\text { forma secreta y privada. }\end{array}$ & Social. \\
\hline 26 & Derechos Humanos & $\begin{array}{l}\text { DRHOS } \\
\text { HMNOS }\end{array}$ & $\begin{array}{l}\text { Se basan en el respeto por las personas en lo } \\
\text { moral y racional, tratando a todos con dignidad. }\end{array}$ & Social. \\
\hline 27 & Calidad de Vida & CDAD VDA & $\begin{array}{l}\text { Niveles óptimos de condiciones económicas, } \\
\text { sociales, políticos, salud y condiciones naturales. }\end{array}$ & Social. \\
\hline 28 & $\begin{array}{l}\text { Investigación y } \\
\text { Desarrollo }\end{array}$ & $\begin{array}{l}\text { INV. Y } \\
\text { DSALLO }\end{array}$ & $\begin{array}{l}\text { Estudios para mejorar las prácticas productivas } \\
\text { y el desarrollo de las comunidades indígenas del } \\
\text { Departamento del Cauca }\end{array}$ & $\begin{array}{l}\text { Tecnológico y } \\
\text { Económico }\end{array}$ \\
\hline 29 & Logística & LGTICA & $\begin{array}{l}\text { Previsión. Organización y control de materias } \\
\text { primas, productos desde su inicio hasta el } \\
\text { consumidor final }\end{array}$ & Tecnológico. \\
\hline 30 & CALIDAD & CDAD & $\begin{array}{l}\text { La calidad de los productos, el servicio al cliente } \\
\text { o consumidor basado en el compromiso de las } \\
\text { comunidades indígenas y Reinsertados. }\end{array}$ & Educativo. \\
\hline
\end{tabular}

Fuente: elaboración propia

En el análisis estructural se realiza el análisis las influencias directas entre variables tomadas por pares. También se evalúa su intensidad por medio de apreciaciones cualitativas tales como: fuerte (grado 3), mediana (grado 2), débil (grado 1) o potencial (Balbi, 2004, p. 12).
A partir de la evaluación de la influencia de las variables según la calificación dada por los expertos se logran identificar las diferentes variables: variables clave, variables resultado, variables relé y variables autónomas como se muestra en la figura 7 . 


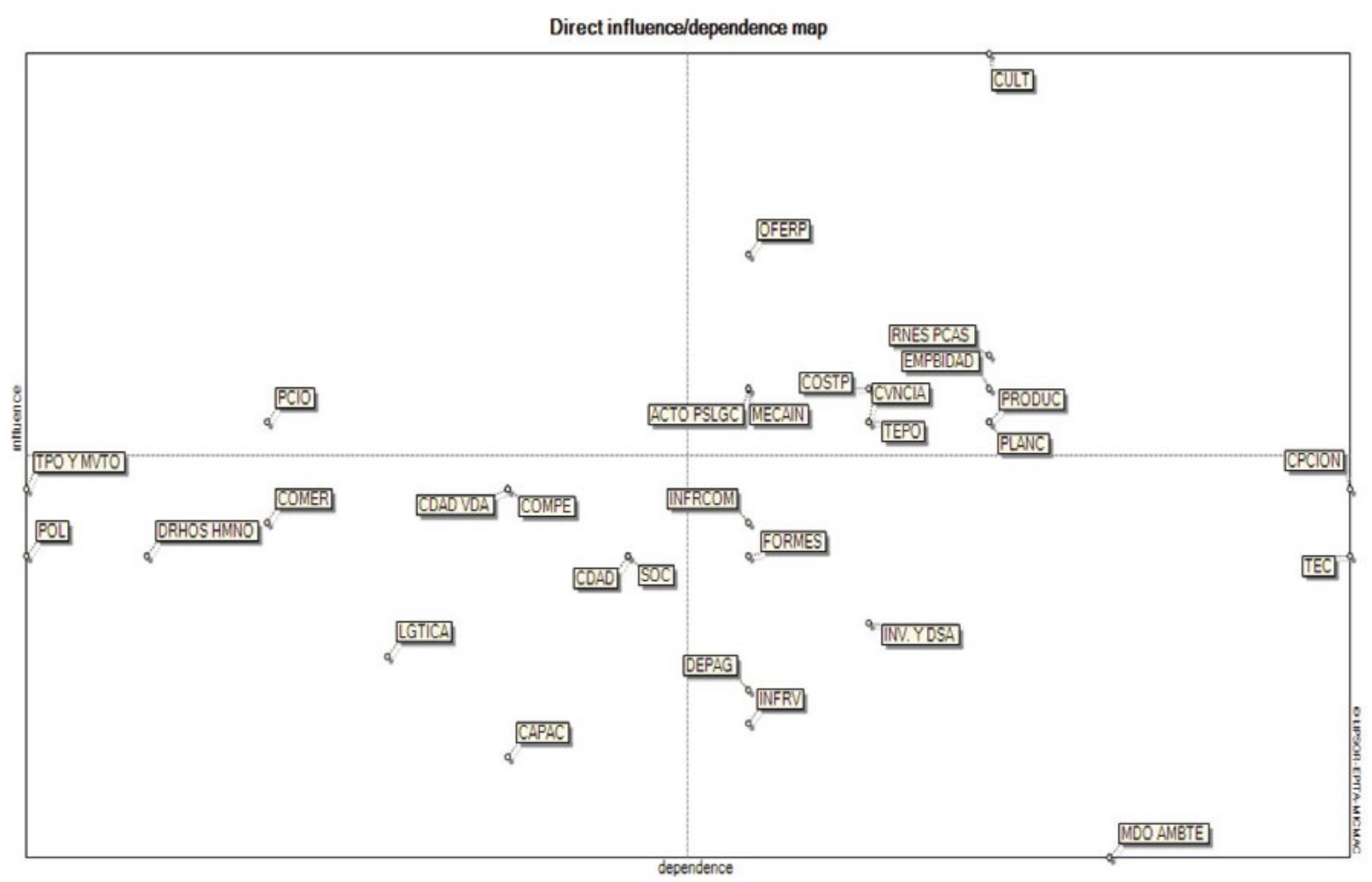

Figura 7. Plano de influencias y dependencias directas.

Fuente: elaboración propia a partir de Godet (2009). Lipsor de Francia

Como resultado de las variables se observa la siguiente clasificación de las variables según su grado de influencia y dependencia - de menor a mayor-, teniendo en cuenta la valoración dada en las matrices respectivas. En el objeto de estudio se encontraron treinta variables en el entorno, que fueron estudiadas para realizar una proyección mediante el grafico de influencias por dependencia, permitiendo identificar las cuatro categorías de variables; que se diferencian entre sí dependiendo de la función específica que pueden desempeñar en el objeto de estudio.
Variables clave determinantes o "influyentes". Las encontramos en el cuadro superior derecho del gráfico, son muy influyentes y un tanto dependientes, generando una fuerte influencia en el sistema, dependiendo de cuánto podamos controlarlas como un factor clave de inacción o de movimiento, estas variables son decisivas, además existen variables del entorno que condicionan fuertemente el sistema, pero en general no pueden ser controladas por éste. A continuación, relacionamos las variables encontradas: culturales, oferta de productos, acompañamiento psicológico, mecanismo de información, 
costos de producción, Plan Colombia, -ahora paz Colombia-, trabajo en equipo, empleabilidad, convivencia y productividad

\section{MÉTODO MACTOR}

Método de análisis de juego de actores, Mactor busca valorar las relaciones de fuerza entre los actores y estudiar sus convergencias y divergencias con respecto a un cierto número de posturas y de objetivos asociados, cuyo objetivo es el de facilitar a un actor una ayuda para la decisión de la puesta en marcha de su política de alianzas y de conflictos (Godet, 2000, p. 81).

Por lo anterior a continuación se presentan los actores más relevantes que están relacionados no solamente con las actividades productivas de las comunidades indígenas en el departamento del Cauca, sino los que están involucrados con el proceso de paz.

Tabla 2. Actores que están involucrados en las actividades productivas.

\begin{tabular}{|c|c|c|c|}
\hline $\mathbf{N}^{\circ}$ & Título largo & Título corto & Descripción \\
\hline 1 & Iglesia católica & IGLC & Organización religiosa \\
\hline 2 & Policia Nacional & PONAL & $\begin{array}{l}\text { Organización perteneciente a las Fuerzas } \\
\text { Militares de Colombia adscritas al } \\
\text { Ministerio de Defensa }\end{array}$ \\
\hline 3 & Medios de comunicación & MCOM & Medios de divulgación de la información. \\
\hline 4 & Defensoria del Pueblo & DEFPU & $\begin{array}{l}\text { Organización encargada de velar por los } \\
\text { derechos fundamentales de las personas. }\end{array}$ \\
\hline 5 & Alcaldía Cajibio & ALCACAJ & $\begin{array}{l}\text { Organización encargada de administrar } \\
\text { los recursos de el municipio de Cajibio } \\
\text { (Cauca) }\end{array}$ \\
\hline 6 & $\begin{array}{l}\text { Universidad Nacional, Abierta y a } \\
\text { Distancia }\end{array}$ & UNAD & $\begin{array}{l}\text { Institución de educación superior } \\
\text { comprometida con el postconflicto }\end{array}$ \\
\hline 7 & Sociedad Civil & SOCVIL & Sociedad civil \\
\hline 8 & Consejo Regional Indígena del Cauca & CRIC & $\begin{array}{l}\text { Organización que agrupan a las } \\
\text { comunidades indígenas del departamento } \\
\text { del Cauca }\end{array}$ \\
\hline 9 & Docentes & DOC & $\begin{array}{l}\text { Personas vinculadas a la academia, } \\
\text { encargada de liderar procesos de } \\
\text { formación }\end{array}$ \\
\hline 10 & Organizaciones no gubernamentales & ONG & $\begin{array}{l}\text { Organizaciones cuyos objetivos están } \\
\text { encaminados a apoyar comunidades }\end{array}$ \\
\hline 11 & Afrodescendientes & AFRO & Comunidad afrodescendiente \\
\hline
\end{tabular}


Retos y desafíos de las actividades productivas en las comunidades indígenas del departamento del Cauca en el marco del posconflicto

\begin{tabular}{|l|l|l|l|}
\hline 12 & Paeces & PAEC & $\begin{array}{l}\text { Agrupación indígena del departamento del } \\
\text { Cauca }\end{array}$ \\
\hline 13 & Cámara de Comercio & CAMCOM & Entidad privada sin ánimo de lucro \\
\hline 14 & Estudiantes & EST & $\begin{array}{l}\text { Personas que se encuentran adelantando } \\
\text { procesos de formación en cualquiera de } \\
\text { los niveles }\end{array}$ \\
\hline 16 & $\begin{array}{l}\text { Servicio Nacional de Aprendizaje } \\
\text { SENA }\end{array}$ & SENA & Servicio Nacional de Aprendizaje SENA \\
\hline 17 & $\begin{array}{l}\text { Comité de Integración del Macizo } \\
\text { Colombiano }\end{array}$ & CIMA & Oficina del Alto Comisionado para la paz \\
\hline 18 & Espacio Regional de Paz del Cauca & ERPAZ & $\begin{array}{l}\text { Comité que integra organizaciones } \\
\text { indígenas del Macizo Colombiano }\end{array}$ \\
\hline
\end{tabular}

Fuente: elaboración propia

A partir de este listado de actores que están indígenas del departamento del Cauca en involucrados en las actividades productivas el marco el postconflicto, para esto se debe de las comunidades indígenas se identifica- establecer el grado de influencia que posee rán los de mayor influencia o actores enlace cada actor con respecto a los demás, a través que contribuirán al fortalecimiento de las de la siguiente escala de valoración (Godet, actividades productivas de las comunidades 2009, p. 60).

$0=$ No tiene influencia sobre el actor.

1= Ejerce influencia sobre los procesos del actor.

2= Ejerce influencia sobre los proyectos del actor.

3= Ejerce influencia sobre la misión del actor.

4= Ejerce influencia sobre la existencia del actor.

De esta calificación en la figura 8 podemos observar el grado de influencia y dependencia que tienen los actores. 


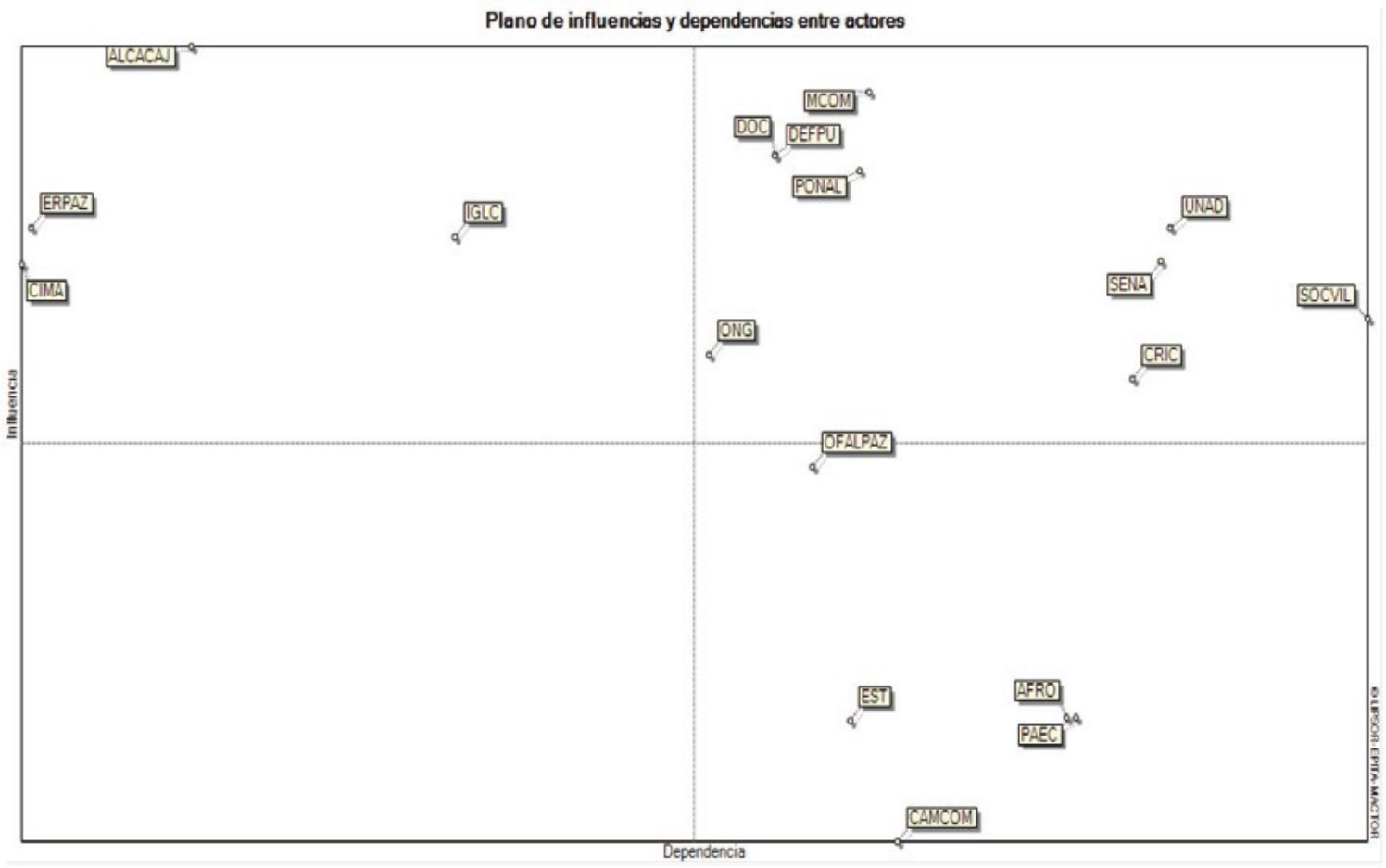

Figura 8. Plano de influencias y dependencias entre actores. Fuente: elaboración propia a partir de Godet, M (2009). Lipsor de Francia

En el plano de influencias y dependencias entre actores, podemos observar la clasificación o tipología de juego del actor, según su grado de influencia y dependencia en las actividades productivas de las comunidades indígenas del departamento del Cauca en el marco del postconflicto, de la siguiente forma:

- Actores de enlace: se caracterizan por su alto grado de influencia y dependencia de alianzas entre las actividades productivas de las comunidades indígenas del departamento del Cauca en el marco del postconflicto y los siguientes actores: Organizaciones no gubernamentales, Defensoría del Pueblo, Medios de Comunicación, Docentes, Policía Nacional, UNAD, SENA, CRIC y Sociedad Civil y actores dominantes: las comunidades indígenas del departamento del Cauca en el marco del postconflicto los actores dominantes o de alto poder (Mojica, 2008, p. 209), imperan en la visualización del escenario apuesta como son: la Iglesia, la Alcaldía de Cajibio, ERPAZ, y CIMA. 
- Actores dominados: también denominados de bajo poder, donde el grado dependencia es alto y la influencia es baja (Mojica, 2008, p. 209). Se encuentran: la Oficina del Alto Comisionado para la Paz, los estudiantes, los Afrodescendientes y los Paeces y actores autónomos: Se determinan por su poca influencia y poca dependencia sobre los demás actores (Mojica, 2008, p. 209); teniendo presente la Matriz de Influencia Directa entre actores MID, se concluye que en este estudio no se encuentran actores autónomos o de muy bajo poder. Finalmente, la convergencia en términos simples sugiere la coincidencia de ideas, tendencias e intereses entre de estos actores del sistema.

\section{CONSTRUCCIÓN DE ESCENARIOS}

La construcción de escenarios sirve para profundizar el conocimiento del presente y sus tendencias, conforme a supuestos teóricos. Estos supuestos se pueden organizar en un modelo novedoso y ahorrativo. Los escenarios pretenden establecer y controlar relaciones de incertidumbre, a fin de proponer ajustes y medidas de contingencia y se aseguran con la revisión periódica de los guiones propuestos.

\section{ESCENARIO APUESTA CAUCA 100\% PRODUCTIVO}

Actualmente las actividades productivas en las comunidades indígenas del departamento del Cauca se desarrollan en forma sectorizada y con un nivel medio de productividad, es por esto que el factor tecnológico debe ser fundamental para el fortalecimiento de las mismas; ya que permite mejorar las técnicas de siembra, cultivo, cosecha, poscosecha y los procesos de producción, sin descuidar la protección del medio ambiente; el gobierno se debe comprometer con las comunidades indígenas del departamento del Cauca para invertir los recursos destinados a la reforma agraria, estipulados en el punto uno de los acuerdos de paz.

Es importante el apoyo económico a entidades como el Consejo Regional Indígena del Cauca (CRIC), que es la organización que agrupa a más del $90 \%$ de las comunidades indígenas del departamento del Cauca; ya que estas le apuestan al desarrollo rural y a los beneficios de trabajar mediante cadenas productivas y la asociatividad, con la finalidad de aumentar la calidad de los productos y el volumen de producción y venta.

Las comunidades indígenas del departamento del Cauca deben implementar buenas prácticas ambientales a la hora de preparar las tierras para que sean fértiles y productivas, deben conocer sobre cadenas productivas y asociatividad, técnicas de siembra, cuidado y recolección de alimentos, protección del medio ambiente y logística y transporte de productos, 
con estos conocimientos se logrará un efectivo desarrollo rural en las comunidades indígenas que generaran una mejor calidad de vida para sus habitantes y los productos ofrecidos serán de calidad y confianza para sus clientes. Al ser contribuyentes de buenas prácticas ambientales y se verán los resultados en el mediano y largo plazo.

Tanto el Gobierno, como las comunidades indígenas, las comunidades afro descendientes, el personal reinsertado y demás organizaciones comprometidas en el progreso y desarrollo rural, deben trabajar arduamente en beneficio de las actividades productivas del departamento del Cauca, en implementar acercamientos o mesas de diálogos - presenciales o virtualespara definir propuestas de trabajo buscando la productividad y competitividad de los productos en el mercado colombiano y generando opciones de exportación a gran escala en sus productos bandera como los son el café y la quinua.

\section{PLAN ESTRATÉGICO}

Según los expertos consultados a partir de la pregunta ¿cuáles estrategias considera usted se deben implementar para lograr la articulación de las actividades productivas de los indígenas en el departamento del Cauca?, la mayoría de expertos respondieron que lo primero que debe desarrollar es la mediación y acompañamiento psicosocial, donde se incluyan planes educativos fortalecidos para las comunidades indígenas y en los sectores de desmovilización, así como la generación de empleo, inversión social, realizar mesas de diálogos periódicas entre las partes afectadas para tratar temas de derechos humanos, justicia, equidad fortalecimiento de las actividades productivas.

Así mismo se debe buscar el acercamiento de la iglesia a las comunidades y excombatientes para ser más tolerantes, para lograr el acompañamiento permanente del Estado en el proceso, construcción de políticas públicas, intervención del sector empresarial y político, programas de regreso a casa y una verdadera reconciliación apoyadas desde el gobierno nacional.

A partir de lo anterior se han planteado programas, planes, proyectos, acciones, actividades y los respectivos responsables para cada uno al igual que un plan de seguimiento que se debe tener en cuenta para lograr el escenario apuesta planteado.

\section{DISCUSIÓN}

Ante el fin del conflicto armado en Colombia es muy importante establecer fuertes políticas anticorrupción, con el fin de combatir a sectores internos en el gobierno que deseen mantener vivo el conflicto para obtener ganancias económicas y 
busquen perjudicar a las comunidades realmente afectadas como por ejemplo las comunidades indígenas del departamento del Cauca; ya que se requieren recursos económicos para el fortalecimiento de las actividades productivas.

Según los expertos, las mejores políticas son las que tienen que ver con el desarrollo agrario integral propuestas por el Gobierno nacional para garantizar la soberanía alimentaria y la generación de empleo en las diferentes regiones del departamento del Cauca al año 2030 serán las que estén encaminadas a asegurar el acceso y uso de la tierra, desarrollo social: salud, educación y vivienda y la erradicación de la pobreza.

\section{Políticas para el fortalecimiento de las actividades productivas}

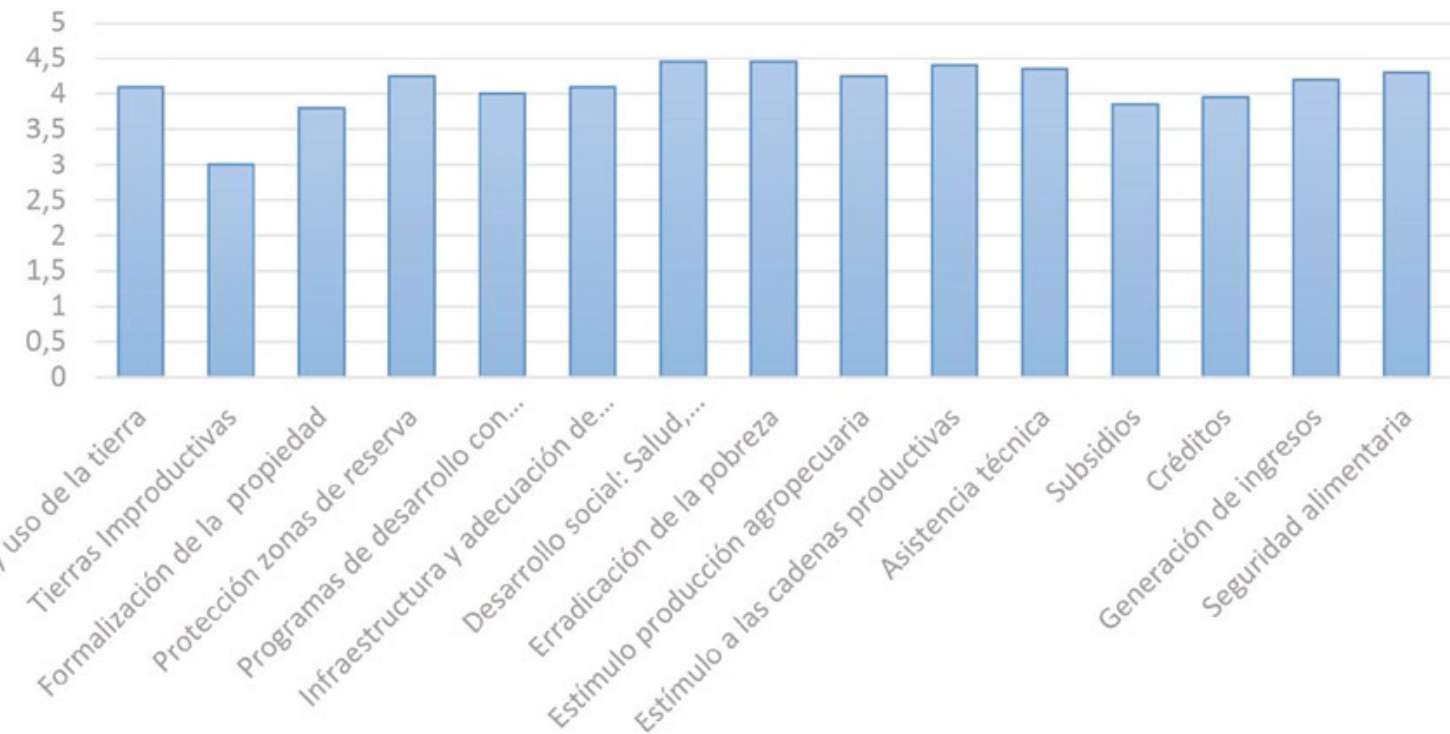

Figura 9. Políticas para el fortalecimiento de las actividades productivas.

Fuente: elaboración propia

Así que según los expertos otras de las principales políticas a tener en cuenta para ser trabajadas al año 2030 y que garanticen estabilidad económica para las comunidades indígenas y suficiente producción alimentaria para el consumo a nivel nacional e internacional deben ser: desarrollo social: salud educación y vivienda, estímulo a la producción agropecuaria, estímulo a la generación de cadenas productivas, erradicación de la pobreza, sistema de seguridad alimentaria y asistencia técnica. 
Por lo anterior la Reforma Rural Integral, contribuirá a la transformación estructural del campo, cerrando las brechas entre el campo y la ciudad y creando condiciones de bienestar y calidad de vida para las comunidades Indígenas del departamento del Cauca, así que los retos y desafíos de las actividades productivas de las comunidades indígenas del departamento del Cauca en el marco de posconflicto al año 2030, deben ser la capacitación a esas comunidades indígenas donde a partir de la investigación y desarrollo se logre el fortalecimiento de esas actividades productivas y de igual manera se busque que el gobierno invierta en la infraestructura vial que permita la comercialización de productos

Otro reto importantes es la asociación en cadenas productivas que generara un verdadero trabajo en equipo y un desarrollo rural efectivo, mostrando así que la verdadera riqueza de una nación está en su gente, en la creación de un ambiente propicio para que los seres humanos disfruten de una vida prolongada, saludable y rodeada de sus seres queridos, acompañada de un conjunto de oportunidades que permitan a las regiones recomponer el tejido social y económico que garanticen una mejor calidad de vida, donde se involucre a los diferentes actores que pueden lograr el fortalecimiento de las actividades productivas de las comunidades indígenas.

\section{CONCLUSIONES}

Dentro de los principales retos y desafíos que los diferentes actores deben enfrentar para el fortalecimiento de las actividades productivas de las comunidades indígenas del departamento del Cauca están la capacitación, la investigación y desarrollo, la productividad, el mejoramiento de la infraestructura vial para la comercialización de productos, conocimiento de los procesos en la preparación de las tierras para que sean fértiles y productivas, conocimiento sobre cadenas productivas y asociatividad, técnicas de siembra, cuidado y recolección de alimentos, trabajo en equipo y protección del medio ambiente.

Para lograr enfrentar los retos y desafíos es importante contar con todos los actores sociales, económicos, políticos, de las universidades, los empresarios, las ONG, de las gobernaciones a las comunidades de base, de los individuos a las organizaciones de la comunidad en general donde cada uno tendrá un rol a desempeñar en el fortalecimiento de las actividades productivas de las comunidades indígenas del departamento del Cauca.

Las comunidades indígenas, campesinas, los reinsertados a la vida civil y los diferentes actores víctimas de la violencia deben participar continuamente en talleres, conferencias y actividades de reintegración y de desarrollo 
agrario a largo plazo; con el fin de acercarse a un futuro emprendedor, social y pacifista.

Para que el acuerdo de la reforma rural integral sea positivo en las comunidades indígenas del departamento del Cauca, este se debe dar a conocer a todos sus habitantes, luego organizar un cronograma de actividades para priorizar los temas más urgentes para cada territorio, con la asistencia permanente de delegados del gobierno, para que las partes tengan seguridad y credibilidad del cumplimiento del acuerdo establecido para el sector rural.

Para enfrentar los retos y desafíos de las actividades productivas del departamento del Cauca, se debe capacitar a las comunidades indígenas para que desarrollen adecuadamente las funciones del campo y manejen correctamente las herramientas, procesos y técnicas. Lo anterior para que los productos terminados sean de calidad y sean aceptados por sus clientes para que repitan su compra.

La gobernación del Cauca y el Consejo Regional Indígena del Cauca (CRIC), deben apoyar los proyectos productivos de cada región para que salgan adelante y sean fuentes de ingresos económicos para el sostenimiento de las familias, comunidades y el departamento caucano, buscando siempre trabajar en equipo y conformando cadenas productivas para que tengan más oportunidades de conquistar nuevos mercados.

\section{REFERENCIAS}

ACNUR (1998). Suplemento del tercer informe. La verificación del acuerdo sobre aspectos socioeconómicos y situación agraria. Guatemala (1 de enero a 31 de julio de 1998). Recuperado En: http://www.acnur.org/t3/ uploads/media/COI_397.pdf?view=1

Anónimo. (2014). El Pueblo. Recuperado en: http:// elpueblo.com.co/los-pueblos-etnicos-del-cauca -piensan-el-posconflicto/

Avendaño,M.y Mera,C.(2013). Prospectiva Organizacional. Modulo prospectiva organizacional y estrategia. Universidad Nacional Abierta y a Distancia- UNAD. Recuperado en: http://datateca.unad.edu.co/ contenidos/107034/Entorno_de_Conocimiento/ MODULO_PROSPECTIVA_ORGANIZACIONAL_Y_ ESTRATEGICA_ACTUALIZADO_2013.pdf

Bharadwaj, N., et al. (2007). Nepal at the Crossroads: the nexus between human security and renewed conflict in rural Nepal. Kathmandu: Friends for Peace and International Alert

Bhattarai, A. (2003). A case for radical non-violent politics. In D. Thapa, Understanding the Maoist Movement of Nepal. Kathmandu: Chautari Books. 
https://doi.org/10.22490/issn.2539-2786

Comisión Histórica de Conflicto y sus Victimas. (2015). Contribución al entendimiento del conflicto armado en Colombia. Recuperado en: https://www. mesadeconversaciones.com.co/sites/default/ files/Informe\%20Comisi_n\%20Hist_rica\%20del\%20 Conflicto $\% 20 y \% 20$ sus $\% 20$ V_ctimas. $\% 20$ La $\% 20$ Habana\%2C\%20Febrero\%20de\%202015.pdf

ECP. (2006). Annuario 2006 de procesos de paz. Vicenç Fisas.

El Espectador. (s.f.). Recuperado en: http://www. elespectador.com/noticias/redes-sociales/50anos-de-conflicto-armado-colombia-alfredomolano-articulo-545707

El Heraldo. (2016) . Las teorías del origen del conflicto armado en Colombia. Recuperado en: http://www. elheraldo.co/politica/las-teorias-del-origen-delconflicto-armado-en-colombia-184562

El Tiempo. (s.f.). Recuperado en: http://www.eltiempo. com/noticias/conflicto-armado-en-colombia

Gabiña, J., (1999). Prospectiva y planificación territorial. Hacia un proyecto de futuro. Bogotá, Colombia: Alfaomega.
Gobernación del Departamento del Cauca. (2015). Reflexiones Caucanas ante los diálogos de La Habana: Análisis cartográfico frente a los posacuerdos de paz (Reintegración, riesgos de violencia y paz desde el territorio). Colombia

Godet, M., (2000). La Caja de Herramientas de la Prospectiva Estratégica. España: Prospektiker Instituto Europeo de Prospectiva y Estrategia.

Godet, M., (2007). El rigor de una disciplina intelectual en prospectiva estratégica: problemas y métodos. Cuadernos de Lipsor.

Godoy, S. L. (2014). Corporación Nuevo Arcoiris. Obtenido de Cauca en el postconflicto. Recuperado en: http://www.arcoiris.com.co/2014/07/cauca-en-elpostconflicto/

Gómez, C. (2003). El postconflicto en Colombia: desafío para la Psiquiatria. Recuperado en: http://www.imbiomed. com/1/1/articulos.php?method=showDetail\&id_ revista=115\&id_seccion=1782\&id_ejemplar=2558\&id_ articulo $=24831$

La Razón Pública. (s.f.). Recuperado en: http://www. razonpublica.com/index.php/conflicto-drogas-ypaz-temas-30/8274-las-diferentes-formas-deentender-el-conflicto-armado-en-colombia.html 
Mojica, J. (2005). La construcción de futuro. Concepto y modelo de prospectiva estratégica, territorial y tecnológica. Buenos Aires, Argentina: Convenio Andrés Bello - Universidad Externado de Colombia.

Mojica, F., (2008). Dos modelos de la escuela voluntarista de prospectiva estratégica. Recuperado en: https:// es.scribd.com/document/95904154/Dos-Modelosde-La-Escuela-Voluntarista-de-Prospectiva

Mojica, J. (2010). Introducción a la Prospectiva Estratégica para la competitividad empresarial. Recuperado en: http://sigug.uniguajira.edu.co/planeacion/word/ documentos/Introducci\%C3\%B3n\%20a\%20la\%20 prospectiva\%20estrat\%C3\%A9gica.pdf

Ortega Mohedano, F. (2008). El método delphi, prospectiva en Ciencias Sociales a través del análisis de un caso práctico. Revista Escuela de Administración de Negocios, 64, 31-54. Recuperado en: http://www. redalyc. org/articulo.oa?id=20612981004

Orjuela, D. (2014). La mala suerte de los diez intentos de paz que ha tenido Colombia. Kyenyke.com. Recuperado en: http://www.kienyke.com/politica/ los-diez-intentos-fallidos-de-proceso-de-paz-encolombia/
Semana. (s.f.). Recuperado en: http://www.semana. com/opinion/articulo/jean-marie-guehennoel-principio-del-fin-del-conflicto-armado-encolombia/418448-3

Semana (2012). Diez puntos clave del proceso de paz. Recuperado en: http://www.semana.com/politica/ articulo/diez-puntos-clave-del-proceso/266501-3

Sepaz. (s.f.). Recuperado en: http://sepaz.gob.gt/ observatorioacuerdos/index.php/ejes-tematicos/ acuerdo-sobre-aspectos-socioeconomicos-ysituacion-agraria/84-ultimas-noticias

Tamayo,H. (2015). Conflicto armado en Colombia:factores, actores y efectos múltiples. Periódico El Mundo. Recuperado en: http://www.elmundo.com/portal/ noticias/derechos_humanos/conflicto_armado_en_ colombia_factores_actores_y_efectos_multiples. php\#.VZVRqvl_Oko

Thapa, D. (2003). Understanding the Maoist Movement of Nepal, Kathmandu. Chautari Books

Federation of Community Forestry User's Group of Nepal. SFM : Sustainable Forest Management. Recovered from: http://www.escolapau.org/img/qcp/nepal_ conflicto_paz.pdf 